Methods Five in-depth interviews were conducted with expert healthcare professionals, identified via a purposive sampling technique. The interview transcripts underwent thematic analysis, and the findings were combined with that of the literature review to develop a Current Practice Survey. This was distributed to the 32 Looked-after Children's teams in the area. All the findings were synthesised to enable exploration of this complex area.

Results The combined findings of the in-depth interviews and current practice survey (response rate 47\%) supported the existing evidence around the importance of infectious diseases, screening, health promotion, and psychological wellbeing. It also provided insights into parental consent as a barrier to immunisation, into risk-taking behaviour and the impact of the immigration process on all aspects of UASCYP's health and wellbeing. An understanding of the refugee experience was crucial; experience in country of origin, in flight, upon arrival in the UK and the possibility of return all impacted on physical, psychological, and social needs. Guidance, training, and resources were thought to be useful, but there was limited specialised training.

Conclusion and recommendations A socioecological framework for carrying out the IHA is proposed, which incorporates all these aspects, placing the child at the centre, and taking into account how their environment and life story impacts on health. Healthcare professionals have an important role in advocating for national and international policies that protect and promote the rights of UASCYPs.

\section{G420 AN INTERIM ANALYSIS OF THE GO-CHILD BIRTH COHORT SHOWS A HIGH PREVALENCE OF NASAL SYMPTOMS IN 12 MONTH OLD CHILDREN}

${ }^{1} \mathrm{E}$ Strange, ${ }^{1} \mathrm{~K}$ Basu, ${ }^{1} \mathrm{H}$ Rabe, ${ }^{2} \mathrm{P}$ Seddon, ${ }^{3} \mathrm{~A}$ Memon, ${ }^{4} \mathrm{C}$ Palmer, ${ }^{4} \mathrm{R}$ Tavendale, ${ }^{4} \mathrm{~S}$ Inglis, ${ }^{5} \mathrm{M}$ Quin, ${ }^{1} \mathrm{~S}$ Mukhopadhyay. 'Academic Department of Paediatrics, Royal Alexandra Children's Hospital, Brighton and Sussex Medical School, Brighton, UK; ${ }^{2}$ Royal Alexandra Children's Hospital, Brighton and Sussex Medical School, Brighton, UK; ${ }^{3}$ Division of Primary Care and Public Health, University of Brighton, Brighton, UK; ${ }^{4}$ Biomedical Research Institute, Ninewells Hospital and Medical School, University of Dundee, Dundee, UK; ${ }^{5}$ Research Midwifery, Brighton and Sussex University Hospitals, Brighton, UK

\subsection{6/archdischild-2015-308599.374}

Aims The aim of this report is to use the GO-CHILD birth cohort to map the prevalence of atopic diseases in children in the UK at 1 year.

Methods GO-CHILD is a multicentre prospective birth cohort study. 2135 infants were recruited antenatally and followed up by questionnaires to determine the prevalence of infections and atopic symptoms at 3, 6, 12 and 24 months. The 12 month questionnaire ascertains atopic symptoms within the first year of life.

Results From the 12261 year questionnaires that have been received, 1123 had been entered and analysed by 3/12/2014. 351 (31\%) children had eczema and of these 169 (48\%) had this condition for over 6 months. 176 (16\%) had experienced dry cough unrelated to infection and 253 (23\%) had experienced wheeze. Of those reporting wheeze, 243 (96\%) had developed the wheeze during or soon after a viral infection, 161 (60\%) had been prescribed salbutamol, 97 (39\%) had attended their GP as an emergency and 47 (19\%) had been admitted to hospital. $523(47 \%)$ of the children were reported to snore at night and $252(22 \%)$ had a runny or blocked nose unrelated to infection: both symptoms are potentially indicators of allergic rhinitis. $187(17 \%)$ reported a reaction to a food item, of which the most common was cow's milk.

Conclusion These interim results show a high prevalence of wheeze, eczema and nasal symptoms in 1 year old children. These data are in line with previous cohort studies. The Manchester Asthma and Allergy Study (MAAS) showed the prevalence of eczema to be $37 \%$ and wheeze to be $28 \%$ at 1 year. The ALSPAC study found the prevalence of eczema and wheeze to be $25.6 \%$ and 23\% respectively between 6 and 18 months of age. However our study shows higher levels of upper respiratory symptoms than MAAS which showed a prevalence of $1-2 \%$ by 1 year.

This study was funded by SPARKS.

\section{G421 THE CURRENT CAUSES AND RISK FACTORS FOR SUDI}

1) Garstang, ${ }^{2} \mathrm{C}$ Ellis, ${ }^{1} \mathrm{P}$ Sidebotham, ${ }^{3} \mathrm{~F}$ Griffiths. ${ }^{1}$ Division of Mental Health and Wellbeing, Warwick Medical School, Coventry, UK; ${ }^{2}$ Faculty of Health and Life Sciences, Coventry University, Coventry, UK; ${ }^{3}$ Division of Health Sciences, Warwick Medical School, Coventry, UK

\subsection{6/archdischild-2015-308599.375}

Aims Since 2008, in England, all unexpected child deaths undergo a multi-agency investigation with the aim of determining the complete cause of death; followed by review by local Child Death Overview Panels (CDOP). These new processes have yet to be evaluated. This study aims to determine the effectiveness of the multi-agency investigation and CDOP processes in ascertaining causes of death and risk factors following Sudden Unexpected Death in Infancy (SUDI) and to describe the profile of causes and risk factors.

Methods We obtained the dates of birth and death of all SUDI cases from one English region, dying between 1 September 2010 and 31 August 2012. We contacted all 10 CDOP for copies of individual case reviews completed using the standard CDOP Form C. We extracted the age, cause of death and presence of modifiable factors for each case from the Form $\mathrm{C}$ and created a total family and environmental risk factor score by totalling the risk factors.

Results Data were obtained for 65/70 (93\%) SUDI cases. 20/65 (31\%) deaths were due to medical causes; $21 / 65$ (32\%) due to SIDS and 24/65 (37\%) classified as unascertained deaths. Reanalysis of case data suggested that 9 deaths were probably due to accidental asphyxia, with 6 of these involving parents co-sleeping with their infant after consuming excessive alcohol. Unascertained deaths had significantly higher total family and environmental risk factor scores (mean 2.6, 95\% CI 2.0-3.3) compared to SIDS (mean 1.6, 95\% CI 1.2-1.9), or medical causes for death (mean 1.1, 95\% CI 0.8-1.3). 9/20 (47\%) of medical deaths. 19/21 (90\%) SIDS and 23/24 (96\%) unascertained deaths were considered to be preventable. There were inadequacies in medical provision identified in $5 / 20$ (25\%) of medically explained deaths.

Conclusions The new multi-agency child death processes are effective at determining cause of death and risk factors for SUDI but potential asphyxia deaths may not be recognised. Most deaths labelled as unascertained fulfilled diagnostic criteria for SIDS. Many SUDI occurred in families with mental illness, drug or alcohol misuse and chaotic lifestyles and most in unsafe sleepenvironments. 